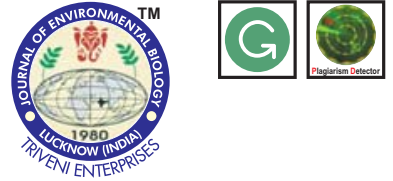

DOI: https://doi.org/10.22438/jeb/38/3/MS-219

ISSN: 0254-8704 (Print) ISSN: 2394-0379 (Online) CODEN: JEBIDP

\title{
Detection and partial molecular characterization of sugarcane mosaic virus infecting sugarcane genotypes
}

Authors Info

S. K. Holkar ${ }^{1 *}$, A. Kumar', M. R. Meena ${ }^{2}$ and R. J. Lal

${ }^{1}$ Division of Crop Protection, ICARIndian Institute of Sugarcane Research, Lucknow-226 002, India

'Division of Plant Breeding, ICAR-Sugarcane Breeding Institute, Regional Station, Karnal, Haryana-132 001, India

*Corresponding Author Email : somnathbhu@gmail.com

Key words

Genome characterization, Phytogenic analyses, Potyvirus,

Saccharum spp.,

Sugarcane mosaic virus

Publication Info

Paper received : 03.12 .2015

Revised received : 12.04 .2016

Re-revised received : 04.10.2016

Accepted:05.11.2016

\section{Abstract}

Aim: Sugarcane mosaic virus (SCMV) is one of the causal agents of mosaic disease of sugarcane in India. Present investigation was carried out to detect association of specific virus with SMD and its molecular characterization.

Methodology: Thirty eight sugarcane genotypes showing mild, severe and necrotic mosaic symptoms were confirmed with the association of flexuous filamentous virion particles by electron microscopy. Of 38 symptomatic sugarcane samples only four samples were subjected to RT-PCR using Potyvirus universal primers which covers amplification of genomic regions viz., partial NIb, full CP and 3'UTR of approximately 1800 bp products. PCR amplicons were cloned in pGEMT Easy vector system. Seven recombinant clones were confirmed by colony PCR, restriction digestion with EcoRI and sequencing.

Results: Of these seven recombinant clones, restricted with EcoRI restriction enzyme, in two clones two fragments of approximately 1600 and 200 bp sizes were obtained, whereas rest of the five recombinant clones showed three restricted fragments of approximately 950,550 and 300 bp which confirmed the variability in the genome of SCMV isolates infecting sugarcane genotypes.

Interpretation:The sequence analysis of partial NIb, full CP and full 3'UTR region of the Karnal, Haryana isolate (KF531632) revealed that, 93-

$96 \%$ sequence identity was found at nucleotide level and $97-98 \%$ identity at amino acid level with the corresponding regions of other SCMV isolates in GenBank. The phylogenic analyses of coat protein (CP) gene showed the clustering of present SCMV_Kar isolate with other SCMV isolates originating from different locations. The present study confirms the association of SCMV with mosaic disease and partia characterization of SCMV Karnal isolate in India.

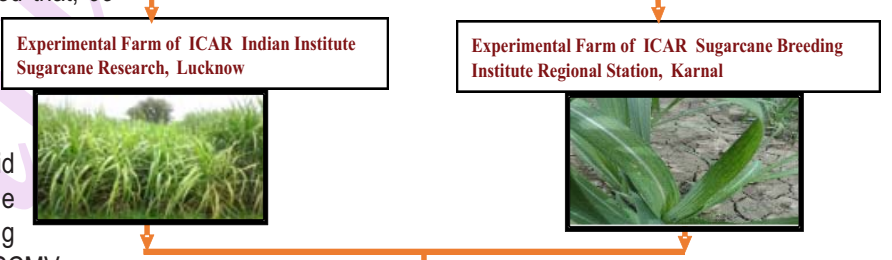

Experimental Farm of ICAR Indian Institute

Diagnosis of Sugarcane mosaic disease (SMD) and molecular characterization of SCMV

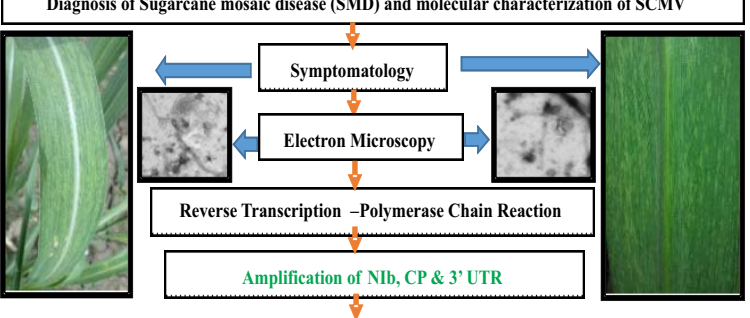

Cloning and sequencing of RT -PCR products

Identity Matrix and Phylogen 


\section{Introduction}

Sugarcane (Saccharum spp.) is one of the most important cash crops in India. The productivity of sugarcane is being hampered by several fungal, bacterial, viral and phytoplasmal diseases across the globe. Among the various viral diseases, sugarcane mosaic disease (SMD) caused by Sugarcane mosaic virus (SCMV) is one of the most important diseases in sugarcane which leads to yield loss up to $10-90 \%$ to the sugar industry (Rao et al., 1998a, b; Viswanathan and Balmuralikrishnan, 2005). SCMV belongs to genus Potyvirus (Family: Potyviridae), infects maize, sorghum and some other graminaceous species (Alegria et al., 2003; Achon et al., 2007). SCMV is characterized by the presence of flexuous filamentous virions which contain a monopartite genome. It is a positive-sense single-stranded RNA virus with a genome size of approximately $10 \mathrm{~kb}$, and is characterized by an un-translated region (5'UTR), a large open reading frame (ORF), and a 3' UTR region that has a poly-adenylated (poly A) tail. The ORF comprises 10 functional proteins including protein $1(\mathrm{P} 1)$, helper component proteinase (HC-Pro), protein 3 (P3), 6K1, cylindrical inclusion protein $(\mathrm{Cl})$, $6 \mathrm{~K} 2$, viral protein genome linked $(\mathrm{VPg})$, major protease of small nuclear inclusion protein (Nla-Pro), large nuclear inclusion protein (NIb), coat protein (CP) (Shukla et al., 1988; Padhi and Ramu, 2011), and PIPO protein (ORF2) (Chung et al., 2008; Wei et al., 2010).

SCMV is transmitted by infected setts, mechanical inoculation and by several aphid species viz., Longiunuis sacchari, Myzus persicae and Rhopalosiphum maidis (Rao and Ford, 2001; Singh et al., 2005). Sugarcane mosaic disease is suppose to cause by more strains of Sugarcane mosaic virus (Jain et al., 1998; Viswanathan and Balmuralikrishnan, 2005). In spite of the fact that, a new causal pathogen of SMD has been reported and named as Sugarcane streak mosaic virus (SCSMV) (Hema et al., 2002, 2003). A mixed infection of SCMV and SCSMV has also been reported in sugarcane in India (Viswanathan et al., 2007; Singh et al., 2009). Although, detection of SCMV and wide spread of disease incidence has been reported from several states of India based on the full and partial coat protein gene, but the studies on partial genome characterization is meagre. Hence, the present study was designed to detect the association of specific Potyvirus species with SMD and partial genome characterization of the SCMV-Kar isolate.

\section{Materials and Methods}

Collection of field samples and storage : Mosaic diseased and healthy samples from 24 sugarcane genotypes viz., Co 94008, Co 1148-242-2, CP 63-369, CYMA08-502, CYMA08-828, CYMA 09-836, CYM 10-25, GU 07-3704, GU 07-3785, GU 07-3803, ISH 99-430, ISH 99-97, ISH 99-92, ISH 99-81, ISH 99-438, KGS 20048, PoJ 279, PoJ 679, PIO 88-1703, WL1120, WL 00-331, WL 00221, WL 00-224 and WL 002248 were collected from the experimental fields at Sugarcane Breeding Institute (SBI), Regional Station, Karnal, Haryana. Similarly, diseased and healthy samples from 14 sugarcane genotypes including, Baragua, Bo 91, Co 0238, CoJ 64, CoLk 94184, CoLk 8102, CoLk 9709, CoLk 7201, CoSe 92423, Co 1148, CoS 767, Co 05011, CoPant 97222 and Khakai were collected from the experimental farm at Indian Institute of Sugarcane Research (IISR), Lucknow, Uttar Pradesh. The collected samples were brought under cold condition and immediately stored in $-80^{\circ} \mathrm{C}$ after freezing in liquid nitrogen till further use in various experiments.

Leaf-dip electron microscopy : The association of virus particles with infected sugarcane samples was ascertained by leaf-dip electron microscopy (Gibbs et al., 1966). Diseased leaf bits $(3-5 \mathrm{~mm}$ ) were cut with help of cork borer macerated on a clean glass slide with a flat ended glass rod in $40-50 \mu$ l phosphate buffer $(0.078 \mathrm{M}, \mathrm{pH} 6.5)$ and left the finally homogenized material for few seconds. A drop of supernatant $(15-20 \mu \mathrm{l})$ from the homogenized virus material was put on the carbon coated grid ( 3 $\mathrm{mm}$ diameter, 400 mesh). Excess of supernatant was then washed off with 180-200 $\mu$ l distilled water. A carbon coated grid was treated with $40-50 \mu \mathrm{l}$ uranyl acetate (aqueous $2 \%$, pH 4.2) for few seconds. Excess stain was removed and blotted dry by touching the edge of the grid with a strip of filter paper. The grid was air-dried for 1-2 min. The negatively stained grid was finally examined under electron microscope (JEM-1011) at the Advanced Centre for Plant Virology, IARI, New Delhi.

Reverse transcription polymerase chain reaction (RT-PCR) : The total RNA was isolated from the SMD affected sugarcane tissues with RNeasy plant mini kit (Qiagen, Chatsworth, CA, USA) according to manufacturer's instructions and the first strand cDNA was synthesized using Potyvirus universal reverse primer by ImProm-II ${ }^{\mathrm{TM}}$ reverse transcriptase kit (Promega, Madison, WI, USA). A $20 \mu \mathrm{l}$ of CDNA reaction mixture contained $10 \mu \mathrm{l}$ of template RNA $(\sim 2.5 \mu \mathrm{g}), 1 \mu \mathrm{l}(\sim 200 \mathrm{ng})$ of reverse primer, $1 \mu \mathrm{l}$ of $10 \mathrm{mM}$ dNTP, $4 \mu \mathrm{l}$ of $5 \mathrm{x}$ buffer, $0.5 \mu \mathrm{l}$ of RNase inhibitor (40 $\mathrm{UI}^{-1}$ ) (Promega Madison, WI, USA) and $2.5 \mu$ l of sterile distilled water and $1 \mu$ l of reverse transcriptase $\left(\mathrm{Um}^{-1}\right)$ was incubated at $42^{\circ} \mathrm{C}$ for 60 min. A first strand CDNA was used as a template for amplification in polymerase chain reaction (PCR) in $50 \mu \mathrm{l}$ of reaction mixture containing $10 \mu \mathrm{l}$ of cDNA, $5 \mu$ l of $10 x$ PCR buffer, $2 \mu \mathrm{l}$ of $10 \mathrm{mM}$ dNTP, $1 \mu \mathrm{l}(\sim 100 \mathrm{ng})$ each of reverse and forward primers (PotyF 5'ACCACAGGATCCGGBAAYAAYAGYGG DCARCC3'and PotyR 5'CACGGATCCCG GG (T) $\left.{ }_{17} 3^{\prime}\right), 1 \mu \mathrm{l} 2.5$ units of Taq DNA polymerase and $30 \mu$ of sterile distilled water. The PCR was conducted in a thermo cycler (Biometra, Germany) with the following temperature conditions: 2 min hot start at $94^{\circ} \mathrm{C}$ followed by 30 cycles of denaturation at $94^{\circ} \mathrm{C}$ for $1 \mathrm{~min}$, annealing for $2 \mathrm{~min}$ at $57^{\circ} \mathrm{C}$, synthesis at $72^{\circ} \mathrm{C}$ for $2 \mathrm{~min}$, and a cycle of final extension at $72^{\circ} \mathrm{C}$ for $10 \mathrm{~min}$.

Cloning, sequencing and sequence analyses : The RT-PCR products were analyzed in $1 \%$ agarose gel electrophoresis at $60 \mathrm{~V}$ 
and purified using SV-gel and PCR clean-up system (Promega Corporation, Madison, WI, USA). Further, these amplicons of Potyvirus, approximately $1800 \mathrm{bp}$, were cloned in pGEM-T Easy vector (Promega Corporation, Madison, WI, USA) and the recombinant clones were screened by colony $P C R$ and restriction digestion with $\mathrm{EcoRI}$ enzyme and the selected recombinant clones were sequenced (primer walking) by automated sequencing facility at Department of Biochemistry, University of Delhi South Campus, New Delhi. The nucleotide (nt) and amino acid (aa) sequence analyses were conducted by clustal W version 1.7 (Thompson et al., 1994) using Bioedit software (www.boiedit.software.informer.com). The phylogenetic tree was constructed by MEGA 5.0 software (http://www. megasoftware.net) and the evolutionary history was inferred using Neighbour-Joining method.

\section{Results and Discussion}

Symptomatology and leaf-dip electron microscopy : The collected sugarcane samples from SBI, Regional Station, Karnal, Haryana and IISR, Lucknow, Uttar Pradesh, exhibited mild, severe systemic mosaic and necrotic spots all over the leaf lamina (Fig. 1A-D). SMD disease was primarily characterized by symptoms observed on cane leaves. Moreover, the symptoms varied with genotype to genotype, but the most distinct symptoms included different shades of light/pale green and dark green along with boat shaped yellowish interveinal chlorotic areas. Subsequently, these interveinal chlorotic spots turned necrotic and reddening of leaf lamina was observed. Symptoms were more prominent on the younger leaves with broad leaf lamina than the older leaves. Total six random samples subjected to EM studies revealed the presence of slightly flexuous rod shaped particles in all the tested genotypes viz., PoJ 279, WL 00-221, Co 94008, Co 1148, PoJ 679 and WL 00-224 (Fig. 1E). During the month of October-November, 2015 the aphid colonies were spotted on mosaic affected Co 0238 and other sugarcane genotypes at IISR farm (Fig. 1F). In order to confirm the association of specific Potyvirus species with SMD, these samples were further subjected to reverse transcription polymerase chain reaction (RT-PCR) using universal Potyvirus primers followed by sequencing.

Detection and molecular characterization of SCMV in sugarcane genotypes : Of six EM positive samples, only four were subjected to RT-PCR. The RT-PCR from four random symptomatic sugarcane samples resulted in the amplification of approximately $1800 \mathrm{bp}$ size products and apparently asymptomatic samples showed no amplification (Fig. 2A). The resulting amplicons were cloned and confirmed by colony PCR and restriction digestion using EcoRI. Restriction digestion using $\mathrm{EcoRI}$ was carried out for seven recombinant clones, the two clones (Fig. 2B; Lanes: 6 \& 7) were restricted into two bands of approximately $1600 \mathrm{bp}$ and $200 \mathrm{bp}$ in contrast to the remaining five recombinant clones resulting in restriction of three fragment sizes of approximately 950 bp, 550 bp and 300 bp (Fig. 2B; Lanes 1, 2, 3, 4 \& 5) along with the TA cloning vector, which might be either due to the presence of other closely related Potyvirus or the same Potyvirus having two restriction sites of EcoRI in the genome since, primers used in this study were universal Potyvirus which detects all the species of Potyviruses. Of these, single clone was sequenced (Fig. 2B; Lane: 6); the sequence of 1828 nucleotides shared maximum $96 \%$ sequence identity with those of Sugarcane mosaic virus isolates at nucleotide level after performing BLAST in GenBank. The sequence of SCMV_Karnal, Haryana (SCMV_Kar) isolate from the present study was submitted to the GenBank (accession no: KF531632). The sequence of SCMV_Lucknow isolate needs further characterization.

The characterized partial polyprotein of SCMV_Kar isolate is composed of 1828 nucleotides of which 639, 1138 and 246 nucleotides corresponding to partial $\mathrm{Nlb}$ region, complete coat protein (CP) gene and 3' UTR with poly (A) tail, respectively. Earlier, it was reported that the coat protein composed of three types of $\mathrm{N}$ terminal $\mathrm{CP}$ region sequences and similar findings suggested by Alegria et al. (2003) and Chen et al. (2002). Type one includes the isolates originating from South Africa (SCMVSA, AF006738), Australia (SCMV-BRIS, AJ278405) and USA (SCMV-USLA, AF006736; SCMV-A, U57354; Handley et al., 1998). Whereas, isolates originating from isolates SCMV-MDB (A34976 and D00949) formed second type and designated as new Potyvirus species (Fan et al., 2003; Handley et al., 1998). Third type composed of isolates originating from China, Germany (SCMV-BOR, X98167) and Mexico (SCMV-Mx, AY195610), later Chinese isolates were divided further as maize and sugarcaneinfecting. SCMV_Kar isolate clustered closely to the type one group isolates originating from USA (AJ278405 and U57354) and shared $97-98 \%$ sequence identity at amino acid level. Moreover, Zhong et al. (2005) identified naturally occurring recombinant isolate of SCMV causing maize dwarf mosaic disease and found that the CP sequences showed about 95\% identities with the SCMV-Mx and SCMV-BOR, suggesting that the maize isolates classed as new strain but not the geographical isolates. Contrastingly, in a recent past association of SCMV with sorghum was reported in Tehran based on the results obtained by DASELISA and RT-PCR with 900 bp amplicons (Mohammadi and Hajieghrai, 2009).

A complete CP gene sequence of SCMV_Kar isolate shared $89-98 \%$ identity with other SCMV isolates infecting maize and sugarcane both at nucleotide and amino acid levels, respectively. Whereas, it shared minimum $79 \%$ and $89 \%$ sequence identity with Sorghum mosaic virus (SrMV) at nucleotide and amino acid levels, respectively (Table 1). Similarly, CP sequence revealed maximum $96-98 \%$ sequence identity with SCMV originating from USA (accession no: U57355, AY953351, U57356 and U57357) and China (accession no: AY953351). In 

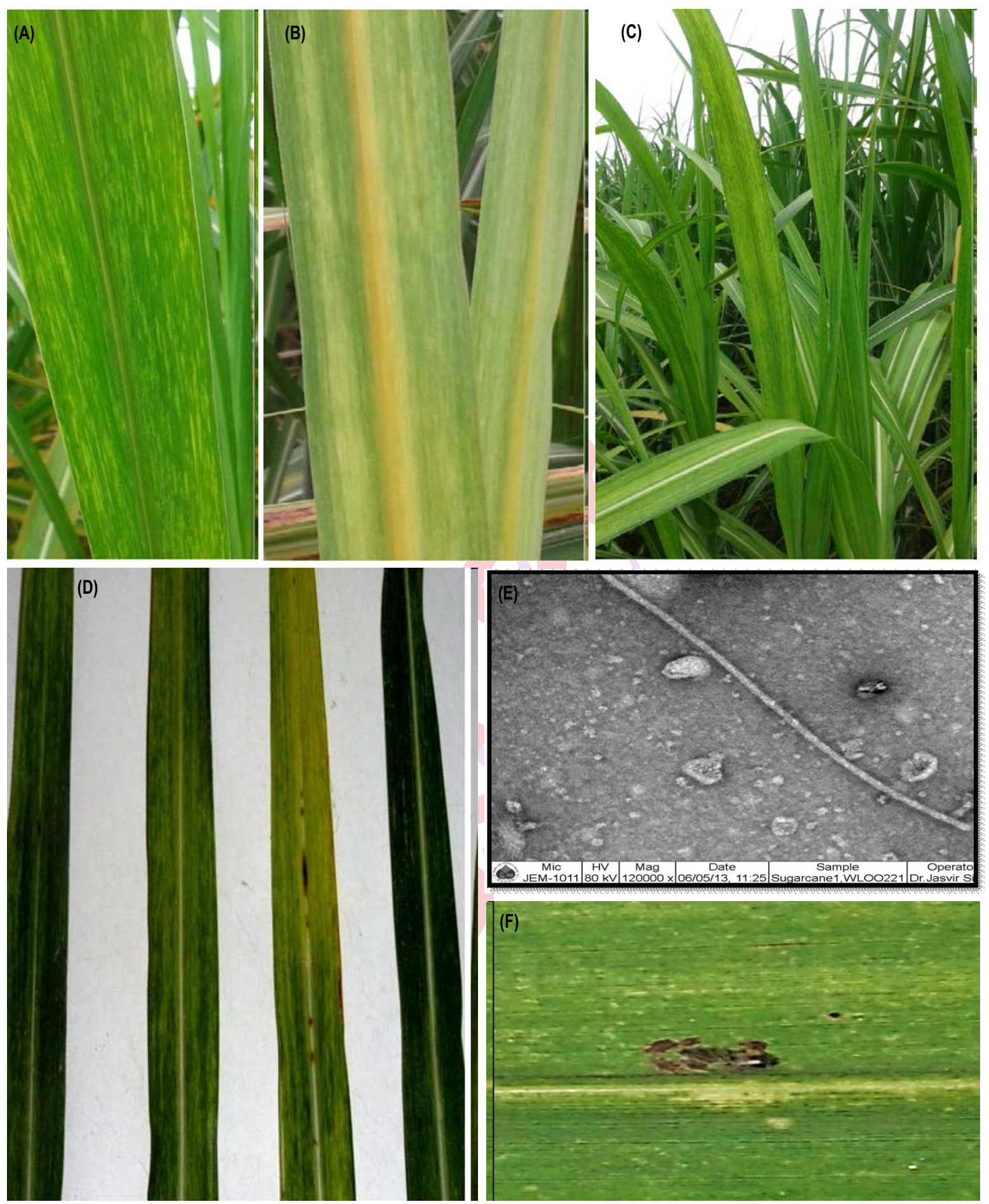

Fig. 1 : Symptoms of Sugarcane mosaic virus (SCMV) on different sugarcane genotypes under field conditions. (A) shades of pale green along with boat shaped yellowish chlorotic areas all over the leaf surface, (B) chlorotic areas on the lower leaf surface, (C) severity of mosaic disease, (D) shades of dark green followed by necrotic spots symptoms varying with four different genotypes, (E) Electron micrographs of Sugarcane mosaic virus (SCMV) virion particles infecting sugarcane genotypes (WL 00221) showing flexuous rods and (F) aphid colonies observed on sugarcane leaves of Co 0238 
(A)

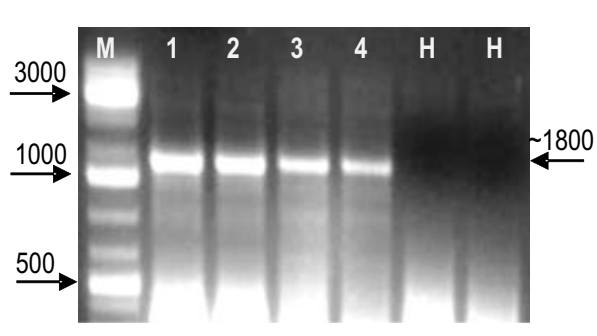

(B)

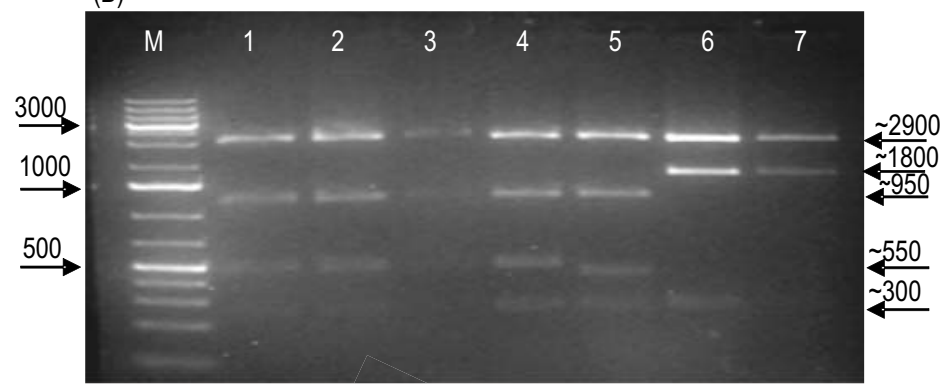

Fig. 2 : Agarose gel electrophoresis of RT-PCR based detection of Sugarcane mosaic virus (SCMV) infecting sugarcane. (A) PCR amplification of sugarcane samples infected by potyvirus using universal primers. Lane: M: 1 kb DNA ladder 1: POJ 679, 2: Co 94008, 3: WL 00-224, 4: Co 1148 H: healthy. (B) Restriction digestion of the recombinant pGEMT clones (1-7) by EcoRI restriction enzyme. The fragment sizes represented in base pairs

\begin{tabular}{|c|c|c|c|c|c|c|c|c|c|c|c|c|c|c|c|c|c|c|c|c|c|c|c|}
\hline $\begin{array}{c}\text { Sequence } \\
\text { Accession No. }\end{array}$ & 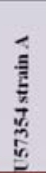 & 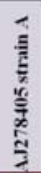 & 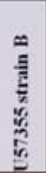 & 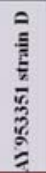 & 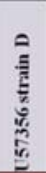 & 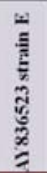 & 章 & $\frac{2}{3}$ & $\frac{\frac{9}{10}}{\frac{1}{2}}$ & 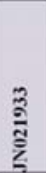 & 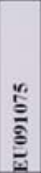 & $\begin{array}{l}\frac{1}{3} \\
\frac{3}{4} \\
\frac{5}{4}\end{array}$ & $\begin{array}{l}\frac{1}{0} \\
\ddot{\alpha} \\
\frac{\alpha}{2}\end{array}$ & $\begin{array}{l}\tilde{B} \\
\tilde{y} \\
\underline{z} \\
\underline{z}\end{array}$ & 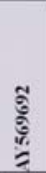 & $\stackrel{\infty}{\frac{\infty}{a}}$ & $\frac{\vec{d}}{\frac{\pi}{3}}$ & $\begin{array}{l}3 \\
\frac{3}{5} \\
\frac{1}{3} \\
\end{array}$ & 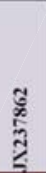 & 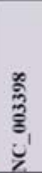 & $\begin{array}{l}\text { đু } \\
\vdots \\
\vdots \\
\vdots\end{array}$ & 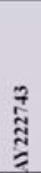 & $\begin{array}{c}5 \% \\
10 \% \\
15 \% \\
20 \%\end{array}$ \\
\hline U57354 strain A & 100 & 95 & 94 & 95 & 94 & 95 & 94 & 93 & 79 & 77 & 81 & 78 & 79 & 80 & 79 & 79 & 80 & 88 & 94 & 80 & 80 & 78 & 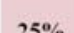 \\
\hline A.J278405 strain A & 95 & 100 & 95 & 97 & 96 & 97 & 96 & 96 & 80 & 78 & 82 & 79 & 79 & 82 & 80 & 80 & 80 & 90 & 97 & 80 & 80 & 79 & \\
\hline U57355 strain B & 94 & 95 & 100 & 95 & 98 & 95 & 95 & 93 & 80 & 77 & 81 & 79 & 79 & 81 & 80 & 80 & 80 & 89 & 95 & 80 & 80 & 79 & \\
\hline AV 953351 strain D & 95 & 97 & 95 & 100 & 96 & 96 & 96 & 95 & 79 & 78 & 82 & 79 & 79 & 81 & 80 & 79 & 80 & 90 & 97 & 80 & 80 & 79 & \\
\hline U57356 strain D & 94 & 96 & 98 & 96 & 100 & 96 & 96 & 94 & 79 & 77 & 81 & 79 & 79 & 81 & 79 & 79 & 79 & 89 & 96 & 79 & 79 & 79 & \\
\hline A) 836523 strain E & 95 & 97 & 95 & 96 & 96 & 100 & 98 & 95 & 80 & 77 & 81 & 79 & 78 & 81 & 80 & 80 & 80 & 90 & 97 & 80 & 80 & 79 & \\
\hline U57357 strain E & 94 & 96 & 95 & 96 & 96 & 98 & 100 & 95 & 80 & 77 & 81 & 78 & 79 & 81 & 80 & 80 & 80 & 90 & 97 & 80 & 80 & 79 & \\
\hline KF531632* & 93 & 96 & 93 & 95 & 94 & 95 & 95 & 100 & 80 & 77 & 82 & 79 & 79 & 81 & 80 & 80 & 80 & 90 & 96 & 80 & 80 & 80 & $55 \%$ \\
\hline AF494510 & 79 & 80 & 80 & 79 & 79 & 80 & 80 & 80 & 100 & 79 & 89 & 79 & 78 & 88 & 99 & 99 & 99 & 79 & 80 & 99 & 99 & 77 & \\
\hline JN021933 & 77 & 78 & 77 & 78 & 77 & 77 & 77 & 77 & 79 & 100 & 80 & 78 & 80 & 80 & 79 & 79 & 79 & 78 & 78 & 79 & 79 & 77 & \\
\hline EU091075 & 81 & 82 & 81 & 82 & 81 & 81 & 81 & 82 & 89 & 80 & 100 & 85 & 79 & 95 & 89 & 89 & 89 & 80 & 82 & 89 & 89 & 79 & $65 \%$ \\
\hline GU47+635 & 78 & 79 & 79 & 79 & 79 & 79 & 78 & 79 & 79 & 78 & 85 & 100 & 91 & 84 & 79 & 79 & 80 & 78 & 79 & 80 & 80 & 80 & \\
\hline JX188385 & 79 & 79 & 79 & 79 & 79 & 78 & 79 & 79 & 78 & 80 & 79 & 91 & 100 & 79 & 78 & 78 & 78 & 80 & 79 & 78 & 78 & 80 & \\
\hline JX185303 & 80 & 82 & 81 & 81 & 81 & 81 & 81 & 81 & 88 & 80 & 95 & 84 & 79 & 100 & 88 & 88 & 88 & 80 & 82 & 88 & 88 & 79 & $75 \%$ \\
\hline IX569692 & 79 & 80 & 80 & 80 & 79 & 80 & 80 & 80 & 99 & 79 & 89 & 79 & 78 & 88 & 100 & 98 & 99 & 79 & 80 & 99 & 99 & 78 & \\
\hline IY 149118 & 79 & 80 & 80 & 79 & 79 & 80 & 80 & 80 & 99 & 79 & 89 & 79 & 78 & 88 & 98 & 160 & 98 & 79 & 80 & 99 & 99 & 77 & b \\
\hline AY042184 & 80 & 80 & 80 & 80 & 79 & 80 & 80 & 80 & 99 & 79 & 89 & 80 & 78 & 88 & 99 & 98 & 100 & 79 & 80 & 100 & 100 & 78 & $85 \%$ \\
\hline JX237863 & 88 & 90 & 89 & 90 & 89 & 90 & 90 & 90 & 79 & 78 & 80 & 78 & 80 & 80 & 79 & 79 & 79 & 100 & 90 & 79 & 79 & 80 & \\
\hline $\begin{array}{l}\mathrm{JX} 237862 \\
\end{array}$ & 94 & 97 & 95 & 97 & 96 & 97 & 97 & 96 & 80 & 78 & 82 & 79 & 79 & 82 & 80 & 80 & 80 & 90 & 100 & 80 & 80 & 80 & $\%$ \\
\hline NC. 003398 & 80 & 80 & 80 & 80 & 79 & 80 & 80 & 80 & 99 & 79 & 89 & 80 & 78 & 88 & 99 & 99 & 100 & 79 & 80 & 100 & 100 & 78 & $95 \%$ \\
\hline 1.1297628 & 80 & 80 & 80 & 80 & 79 & 80 & 80 & 80 & 99 & 79 & 89 & 80 & 78 & 88 & 99 & 99 & 100 & 79 & 80 & 100 & 100 & 78 & \\
\hline $11 / 222743$ & 78 & 79 & 79 & 79 & 79 & 79 & 79 & 80 & 77 & 77 & 79 & 80 & 80 & 79 & 78 & 77 & 78 & 80 & 80 & 78 & 78 & 100 & 6 \\
\hline
\end{tabular}

Fig. 3 : Two-dimensional colour coded (Heat map) graphical representation of pair wise percent sequence identities of the Sugarcane mosaic virus (SCMV) isolates based on coat protein (CP), nuclear inclusion bodies (NIb) and three prime un-translated (3'UTR) region. *represents SCMV-Kar isolate sequence submitted to the GenBank from the present study

contrast to this, the SCMV Karnal isolate from the present study shared maximum $92 \%$ identity at amino acid level with Maize $d$ warf mosaic virus (MDMV) infecting sugarcane originating from Spain. Similar results been described by earlier studies Frenkel et al. (1991) suggesting that CP of SCMV originating from sugarcane (SCMV-SC) shared $92 \%$ identity with MDMV-B and hence these two viruses were considered the strains of the same Potyvirus. Whereas, Jiang and Zhou (2002) observed that the clustering of SCMV in a separate cluster in phylogenetic tree with only SCMV isolates while separate clusters of MDMV, SrMV and
JGMV were clustered in separate clusters resulting in the formation of two groups. The isolates originating from China, Germany, Bulgaria and Spain (infecting maize: group I) and isolates originating from United States, Australia and South Africa (infecting sugarcane: group II) hence, a correlation of sequence pattern of CP with the respective hosts was drawn (Xiao et al., 1993). SCMV_Kar isolate shared maximum $95-96 \%$ identity with the Indian isolates originating from Tamil Nadu, Karnataka and Andhra Pradesh which revealed a maximum variation of $4-5 \%$ with Indian isolates and a maximum variation of $2-3 \%$ at amino 


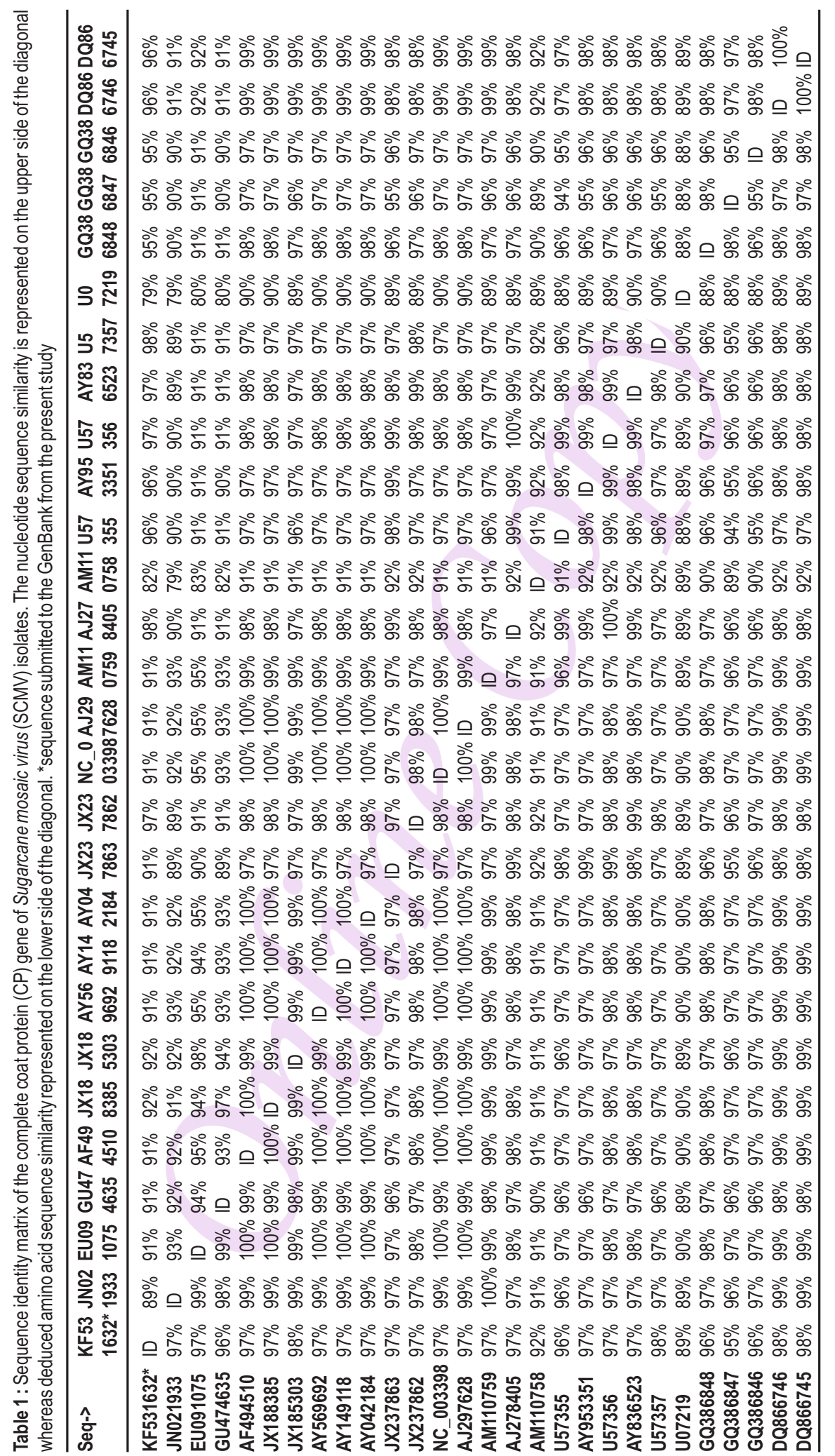


acid level with other SCMV isolates originating from different regions of the world (Table 1). However, based on the earlier reports the sequence data of the NIb coding region of SCMV from Australia, it was found that there was a maximum of $3.3 \%$ variation between isolates at the nucleotide level and a maximum of $0.8 \%$ at the amino acid level (Handley et al., 1996). SCMV_Kar isolates showed a maximum variation of $4-6 \%$ of at nucleotide (nt) level and 2-3\% variation at amino acid (aa) level with all the other

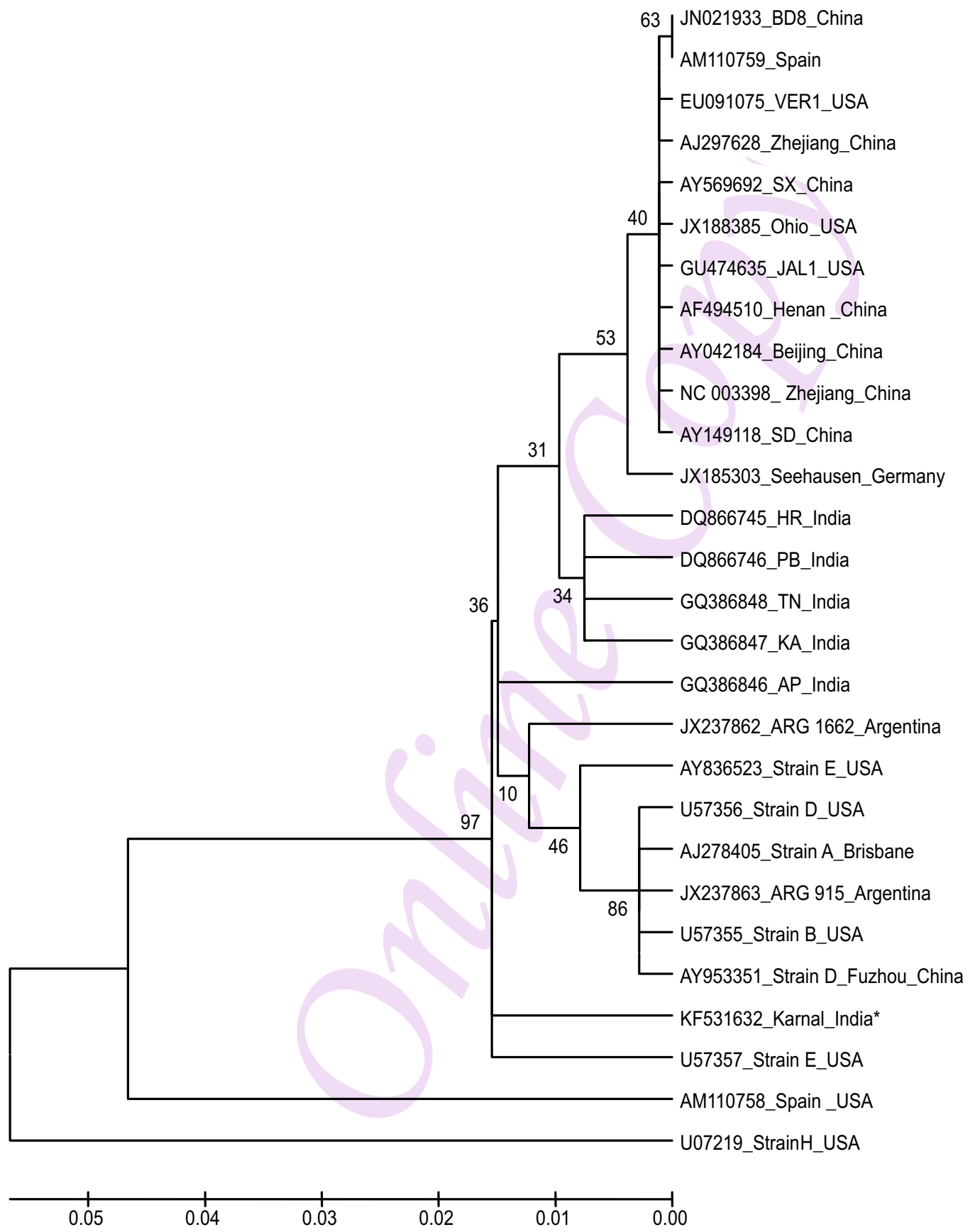

Fig. 4 : Phylogenetic tree (neighbor-joining method with bootstrapping 1000 replicates) constructed based on the comparison of the deduced amino acid sequences of the partial coat protein (CP) gene of Sugarcane mosaic virus (SCMV) isolates. SCMV_Kar isolate from present study showing clustering with SCMV *Sequence submitted to the GenBank from the present study 
isolates of SCMV this forms the existence of maximum genetic variability in SCMV genome. A two-dimensional colour-coded graphical representation of pair wise percent sequence identities among the Sugarcane mosaic virus (SCMV) isolates based on the CP, NIb and 3' UTR showed maximum 95-97\% sequence identity with SCMV_ARG 915 and SCMV_ARG 1962 isolates originating from Argentina, whereas it shared $82 \%$ minimum identity with the MDMV infecting maize from Spain (Fig. 3). The phylogenetic tree revealed close clustering of the KF531632 (SCMV_Kar) isolate with SCMV from USA and Australia, whereas a separate cluster of Indian SCMV isolates from Punjab, Haryana, Tamil Nadu, Karnataka and Andhra Pradesh infecting sugarcane was also observed (Fig. 4).

Antigenic and biological diversity among SCMV isolated from different geographical regions of India had been analysed by ELISA and found SCMV was detected using the SCSMV antiserum (Rao et al., 2004). Subsequently, molecular characterization of SCMV isolated from North Eastern Region (NER) of India was carried out by immuno-based PCR and evidenced that the amino acid sequence showed closest homology with SCMV_SC isolated from Australia (99\%), followed by $97 \%$ with SCMV-A (USA), $87 \%$ SCMV-BJ (China) and 80\% SCMV -MDB (USA), respectively (Gaur et al., 2003). Recently, Adams et al. (2013) identified the association of Maize chlorotic mottle virus (MCMV) and SCMV together with maize lethal necrosis disease, which was not reported so far from India. Moreover, genetic diversity and genomic evidence of intraspecific recombination in SCMV was detected and 6KI-VPg-NlaPro-Nlb region to be recombination hotspot (Li et al., 2013; Padhi and Ramu, 2011) this region was partially characterized in the present study.

In the present study, it was evidenced that the SCMV was associated with SMD and symptoms varied with genotype to genotype at Karnal and Lucknow. However, in Uttar Pradesh, Maharashtra and Tamil Nadu the detection of SCMV and SCSMV was carried out using RT-PCR assays and revealed that SCSMV was found more commonly associated with SMD in India in comparison to the SCMV (Rao et al., 2006). In India, SCMV and SCSMV are the only pathogens of SMD while, SrMV was reported to infect sorghum and maize but not the sugarcane (Rao et al., 2006). Although the mosaic disease caused by SCMV and SCSMV, induced similar symptoms and difficult to differentiate under field conditions, in the present study the association of SCMV with SMD was specifically detected based on the sequence information generated. Expression of symptoms and severity of SCMV varied with genotype to genotype (data not shown), earlier study has been done on the effect of symptom expression in SCMV infected plants on the sugarcane yield and detected the presence of the SCMV population in symptomless genotypes using ELISA (Cronje et al., 1994). Till date from India, 74 total sequences of SCMV (including isolate from present study), SCSMV and SrMV were available at GenBank, of which 45 sequences of SCMV, 15 sequences of SCSMV and 13 sequences of SrMV (http://www.ncbi.nlm.nih.gov). Present study is the evidence of the association of SCMV with the SMD of sugarcane and its partial molecular characterisation (SCMV_Karnal isolate). The molecular characterization of SCMV and/ SCSMV infecting sugarcane in the sub-tropical India would be the future line of research work.

\section{Acknowledgments}

The authors are grateful to the Project Director, NRCPB, New Delhi and the Director, IISR for providing the research facilities at NRCPB, New Delhi and IISR, Lucknow respectively. The help rendered by the Head, Division of Plant Pathology, IARI, New Delhi for processing the samples for EM studies is highly acknowledged.

\section{References}

Achon, M.A., L. Serrano, N.A. Duenas and C. Porta: Complete genome sequences of Maize dwarf mosaic and sugarcane mosaic virus isolates co-infecting maize in Spain. Arch. Virol., 152, 2073-2078 (2007).

Adams, I.P., D.W. Miano, Z.M. Kinyua, A. Wangai, E. Kimani, N. Phiri, R. Reeder, V. Harju, R. Glover, U. Hany and R.S. Richards: Use of next generation sequencing for the identification and characterization of maize chlorotic mottle virus and sugarcane mosaic virus causing maize lethal necrosis in Kenya. Plant Pathol., 62,741-749 (2013).

Alegria, O.M., M. Royer, M. Bousalem, M. Chatenet, M. Peterschmitt, J.C. Girard and P. Rott: Genetic diversity in the coat protein coding region of eighty-six sugarcane mosaic virus isolates from eight countries, particularly from Cameroon and Congo. Arch. Virol., $148,357-372$ (2003).

Chen, J., J. Chen and M.J. Adams: Characterisation of potyviruses from sugarcane and maize in China. Arch. Virol., 147, 1237-1246 (2002).

Chung, B.Y.W., W.A. Miller, J.F. Atkins and A.E. Firth: An overlapping essential gene in the Potyviridae. Proc. Natl.Acad. Sci., 105, 58975902 (2008).

Cronje, C.P.R., G.R. Bechet and R.A. Bailey: Symptom expression of sugarcane mosaic virus (SCMV) and associated effects on sugarcane yield. Proc. S. Afr. Sug. Technol. Ass., 68, 8-11 (1994).

Fan, Z.F., H.Y. Chen, X.M. Liang and H.F. Li: Complete sequence of the genomic RNA of the prevalent strain of a potyvirus infecting maize in China. Arch. Virol., 148, 773-782 (2003).

Frenkel, M.J., J.M. Jilka, N.M. McKern, P.M. Strike, J.M. Clark Jr, D.D. Shukla and C.W. Ward: Unexpected sequence diversity in the amino-terminal ends of the coat proteins of strains of sugarcane mosaic virus. J. Gen. Virol., 72, 237-242 (1991).

Gaur, R.K., G.P. Rao and M. Singh: Molecular characterization of sugarcane mosaic virus of India. Sugar Tech., 5, 149-154 (2003).

Gibbs, A.J., A. Varma and R.D. Woods: Viruses occurring in white clover (Trifolium repens) from permanent pastures in Britain. Ann. Appl. Biol., 58, 231-240 (1966).

Handley, J.A., G.R. Smith, J.L. Dale and R.M. Harding: Sequence diversity in the coat protein coding region of twelve sugarcane 
mosaic potyvirus isolates from Australia, USA and South Africa. Arch. Virol., 143, 1145-1153 (1998).

Hema, M., H.S. Savithri and P. Sreenivasulu: Comparision of direct binding polymerase chain reaction with recombinant coat protein antibody based dot-immunobinding assay and immunocapture-reverse transcription-polymerase chain reaction for the detection of sugarcane streak mosaic disease in India. Curr. Sci., 85, 1774-1777 (2003).

Hema, M., H.S. Savithri and P. Sreenivasulu: Taxonomic position of sugarcane streak mosaic virus in the family Potyviridae. Arch. Virol., 147, 1997-2007 (2002).

Jain, R.K., G.P. Rao and A. Varma: Present status of management of Sugarcane mosaic virus. In: Plant Virus Disease Control. APS Press, Minnesota, pp. 495-523 (1998).

Jiang, J.X. and X.P. Zhou: Maize dwarf mosaic disease in different regions of China is caused by sugarcane mosaic virus. Arch. Virol., $147,2437-2443$ (2002).

Li, Y., R. Liu, T. Zhou and Z. Fan: Genetic diversity and population structure of sugarcane mosaic virus. Virus Res., 171, 242-246 (2013).

Mohammadi, M.R. and B. Hajieghrari: Sugarcane mosaic virus: The causal agent of mosaic disease on sorghum (Sorghum bicolor L.) in Tehran province of Iran. Afr. J. Biotechnol., 8, 5271-5274 (2009).

Padhi, A. and K. Ramu: Genomic evidence of intra-specific recombination in sugarcane mosaic virus. Virus Genes, 42, 282-285 (2011).

Rao, G.P. and R.E. Ford: Vectors of virus and phytoplasma diseases of sugarcane: An overview. In: Sugarcane Pathology, Virus and phytoplasma diseases (Eds.: G.P. Rao, R.E. Ford, M. Tosic and D.S. Teakle). Vol. II, Enfield, Science Publishers, NH, pp. 267-318 (2001).

Rao, G.P., M. Chatenet, J.G. Girard and P. Rott: Distribution of sugarcane mosaic and sugarcane streak mosaic virus in India. Sugar Tech., 8, 79-81 (2006).

Rao, G.P., M. Singh, R.K. Gaur and R.K. Jain: Antigenic and biological diversity among sugarcane mosaic isolates from different geographical regions in India. Indian J. Biotechnol., 3, 538-541 (2004).

Rao, G.P., R.K. Jain and A. Varma: Identification of sugarcane mosaic and maize dwarf mosaic potyviruses infecting poaceous crops in
India. Indian Phytopathol., 51, 10-16 (1998a).

Rao, G.P., R.K. Jain and A. Varma: Characterization and purification of an Indian isolate of sugarcane mosaic virus. Sugar Cane (United Kingdom), 1, 8-10 (1998b).

Shukla, D.D., P.M. Strike, S.L. Tracy, K.H. Gough and C.W. Ward: The N and $\mathrm{C}$ termini of coat proteins of potyviruses are surface-located and the $\mathrm{N}$ terminus contains the major virus-specific epitopes. J. Gen. Virol., 69, 1497-1508 (1988).

Singh, D., A.K. Tewari, G.P. Rao, R. Karuppaiah, R. Viswanathan, M. Arya and V.K. Baranwal: RT-PCR/PCR analysis detected mixed infection of DNA and RNA viruses infecting sugarcane crops in different states of India its phylogenetic relationships to closely related phytoplasmas. Sugar Tech., 11, 373-380 (2009).

Singh, M., A. Singh, P.P. Upadhyaya and G.P. Rao: Transmission studies on an Indian isolate of sugarcane mosaic potyvirus. Sugar Tech., 7 , 32-38(2005).

Thompson, J.D., D.G. Higgins and T.J. Gibson: CLUSTAL W: Improving the sensitivity of progressive multiple sequence alignment through sequence weighting, position-specific gap penalties and weight matrix choice. NucleicAcids Res., 22, 4673-4680 (1994).

Viswanathan, R. and M. Balmuralikrishnan: Impact of mosaic infection on growth and yield of sugarcane. Sugar Tech., 7,61-65(2005).

Viswanathan, R., M, Balamuralikrishnan and R. Karuppaiah. Association of Sugarcane mosaic virus and sugarcane streak mosaic virus with sugarcane mosaic in India. Sugar Cane Inter., 25, 10-18 (2007).

Wei, T.Y., C.W. Zhang, J. Hong, R.Y. Xiong, K.D. Kasschau, X.P. Zhou, J.C. Carrington and A.M Wang: Formation of complexes at plasmodesmata for potyvirus intercellular movement is mediated by the viral protein P3N-PIPO. Plos One Pathol., 6, 962-1000 (2010).

Xiao, X.W., M.J. Frenkel, D.S. Teakle, C.W. Ward and D.D. Shukla: Sequence diversity in the surface-exposed amino-terminal region of the coat proteins of seven strains of sugarcane mosaic virus correlates with their host range. Arch. Virol., 132, 399-408 (1993).

Zhong, Y., A. Guo, C. Li, B. Zhuang, M. Lai, C. Wei and J. Luo: Identification of a naturally occurring recombinant isolate of Sugarcane mosaic virus causing maize dwarf mosaic disease. Virus Genes, 30, 75-83 (2005). 